\title{
E-proteins orchestrate the progression of neural stem cell differentiation in the postnatal forebrain
}

\author{
Bruno Fischer ${ }^{1}$, Kasum Azim ${ }^{1}$, Anahí Hurtado-Chong ${ }^{1}$, Sandra Ramelli ${ }^{1}$, María Fernández $^{1}$ and Olivier Raineteau ${ }^{1,2,3^{*}}$
}

\begin{abstract}
Background: Neural stem cell (NSC) differentiation is a complex multistep process that persists in specific regions of the postnatal forebrain and requires tight regulation throughout life. The transcriptional control of NSC proliferation and specification involves Class II (proneural) and Class V (Id1-4) basic helix-loop-helix (bHLH) proteins. In this study, we analyzed the pattern of expression of their dimerization partners, Class I bHLH proteins (E-proteins), and explored their putative role in orchestrating postnatal subventricular zone (SVZ) neurogenesis.

Results: Overexpression of a dominant-negative form of the E-protein E47 (dnE47) confirmed a crucial role for bHLH transcriptional networks in postnatal neurogenesis by dramatically blocking SVZ NSC differentiation. In situ hybridization was used in combination with RT-qPCR to measure and compare the level of expression of E-protein transcripts (E2-2, $E 2 A$, and $H E B$ ) in the neonatal and adult SVZ as well as in magnetic affinity cell sorted progenitor cells and neuroblasts. Our results evidence that E-protein transcripts, in particular E2-2 and E2A, are enriched in the postnatal SVZ with expression levels increasing as cells engage towards neuronal differentiation. To investigate the role of E-proteins in orchestrating lineage progression, both in vitro and in vivo gain-of-function and loss-of-function experiments were performed for individual E-proteins. Overexpression of E2-2 and E2A promoted SVZ neurogenesis by enhancing not only radial glial cell differentiation but also cell cycle exit of their progeny. Conversely, knock-down by shRNA electroporation resulted in opposite effects. Manipulation of E-proteins and/or Ascl1 in SVZ NSC cultures indicated that those effects were Ascl1 dependent, although they could not solely be attributed to an Ascl1-induced switch from promoting cell proliferation to triggering cell cycle arrest and differentiation.
\end{abstract}

Conclusions: In contrast to former concepts, suggesting ubiquitous expression and subsidiary function for E-proteins to foster postnatal neurogenesis, this work unveils E-proteins as being active players in the orchestration of postnatal SVZ neurogenesis.

Keywords: Class I basic helix-loop-helix proteins, E-proteins, Neural differentiation, Postnatal neurogenesis, Stem cell plasticity

\section{Background}

The self-renewal versus differentiation of neural stem cells (NSCs) into new neurons is a highly complex process and depends on tight regulatory mechanisms throughout postnatal life. Early after birth, radial glia cells (RGCs) mature into type-B cells that reside in the germinal niche lining the lateral ventricles (LVs), namely the subventricular zone (SVZ). These NSCs proliferate slowly (infrequently)

\footnotetext{
* Correspondence: raineteau@hifo.uzh.ch

'Brain Research Institute, ETH Zurich/University of Zurich, 8057 Zurich, Switzerland

${ }^{2}$ Stem Cell and Brain Research Institute, Inserm U846 Lyon, 69675 Bron, France

Full list of author information is available at the end of the article
}

and by asymmetric division give rise to fast proliferating cells, defined as type-C cells (or transit amplifying progenitors). After 3 to 4 cycles of symmetric divisions, allowing the pool of type-C cells to enlarge, these progenitors start to differentiate and commit to specific fates [1]. At this stage, they are defined as type-A cells (or neuroblasts), which then migrate through the rostral migratory stream (RMS) into the olfactory bulb $[2,3]$ to terminally differentiate into specific neuron subtypes (i.e., periglomerular neurons and granule cells) [4].

To balance NSC maintenance and precursor differentiation into neurons or glial cells, postnatal neurogenesis relies on the timely integration of intracellular signaling mechanisms such as the basic-helix-loop-helix (bHLH) 
transcription factor machinery. bHLH proteins represent a large family of transcription factors that are categorized in several classes based on their structure and function [5] and are believed to play an essential role in multiple aspects of forebrain development. By virtue of their transcriptional activity, bHLH proteins can be subdivided into three groups, i.e., activators (Class II), repressors (Class $\mathrm{V})$, and transactivators (Class I) [6].

The classical view of bHLH protein interaction and function is still largely based on drosophila studies [7-9] and murine developmental studies [5,10-12]. There, bHLH repressors (i.e., Hes and Id proteins) and activators (proneural proteins, i.e., Ascl1, Neurog2) mutually antagonize each other either by direct transcriptional repression $[13,14]$, physical inhibition $[8,15]$, or by competing for bHLH transactivators (E-proteins) [12,16]. This antagonistic balance defines whether NSCs or their progeny are differentiating or not, with bHLH repressors predominantly favoring the retention of cells in immature stages $[17,18]$, while bHLH activators accelerate progenitor maturation [13,14,19-22].

Recent work done in drosophila, however, indicates that this established paradigm is likely to be over-simplified and incomplete. A more sophisticated spatial and temporal regulation of E-protein expression has been proposed, suggesting that E-proteins $(E 2-2, E 2 A, H E B)$ fulfill a more complex function than anticipated in germinal zones of the central nervous system (CNS) [23,24]. Furthermore, work in rodents implies that various E-proteins exhibit differential patterns of expression at distinct ages, resulting in the preferential formation of specific dimers [25-27].

This complex pattern of expression, paired with a recent study implicating Ascl1 in regulating both NSC proliferation and differentiation [22], suggests that E-proteins orchestrate NSC lineage progression, a hypothesis we examine in the present study.

\section{Results}

Heterodimerization of Class I/II bHLH proteins is essential for normal NSC differentiation in vitro and in vivo

NS5 cell cultures contain homogenous populations of progenitors that divide indefinitely upon exposure to FGF2 and EGF and undergo neuronal and glial differentiation following mitogen withdrawal [28]. Overexpression of proneural proteins, such as Ascl1, in progenitors of various origins results in their rapid neuronal differentiation [19-22].

In the first instance, the role of Class I/II bHLH factors in mediating neurogenesis was assessed in vitro. The efficiency of neuronal differentiation following overexpression of Ascl1 alone or in combination with E-proteins when NS5 cells were grown in proliferative culture conditions was determined. Overexpression of Ascl1 induced a $>3$-fold increase in neuronal differentiation compared to an empty control plasmid, as revealed by elevated Map2 or CD24 transcript expression, both of which are immature neuron markers (Figure 1A). Cotransfection of Ascl1 with either E-protein, i.e., E2-2, $E 47$ ( $E 2 A$ isoform), and $H E B$, further potentiated Ascl1-induced neuronal differentiation by approximately 50 to $80 \%$ when Map 2 expression was measured, and to a lesser extent when CD24 transcription was probed (Figure 1A). In contrast, measurement of $A B C G 2$, a transcript expressed in NSCs, showed opposite trends (Figure 1A). Together, these results illustrate the interchangeability of E-proteins in this cellular context and their potential to promote Ascl1-induced NS5 cell differentiation.

We next disrupted Class I/II bHLH transcriptional activity in vitro and in vivo to investigate its effect on NSC differentiation. We used a mutated form of the $E 2 A$ isoform E47, which lacks its nuclear localization sequence and fails to translocate to the cell nucleus, and therefore sequesters its binding partners within the cytoplasm [29,30] (Figure 1B,D (insert)). While overexpression of dominant-negative E47 ( $d n E 47)$ alone did not influence Map2 transcript expression in proliferative culture conditions (Additional file 1A), it efficiently prevented Ascl1-induced neuronal differentiation of NS5 cells as shown by the partial blockade of Map2 induction (Figure 1C). We next tested the effect of $d n E 47$ in SVZ NSCs (i.e., radial glia cells (RGCs) at this early postnatal stage) by performing postnatal in vivo electroporation. Early after birth, NSCs can be easily distinguished from their progeny based on morphological criteria, i.e., an elongated cell body and the presence of a basal and apical process [31,32]. Quantification revealed a dramatic blockade of differentiation following $d n E 47$ overexpression, with most electroporated $\mathrm{RFP}^{+}$cells still presenting a clear RGC morphology (Figure 1D,E). Interestingly, cells that were already undergoing differentiation into non-radial glial cells (non-RGCs) exhibited an enhanced proliferative phenotype, as demonstrated by the doubling of the number of $\mathrm{Ki}^{+} 7^{+} / \mathrm{RFP}^{+}$non-RGCs (Figure 1F, Additional file $1 \mathrm{~B})$.

To confirm the accuracy in monitoring RGC differentiation progression by electroporation and analysis of morphological criteria, we next performed an in depth antigenic characterization of RGCs and non-RGCs. At 2 days post-electroporation (2 dpe), RGCs were highly positive for type-B cell markers (i.e., Vimentin and Hes5-EGFP) and completely devoid of the type-C cell marker Ascl1 (Figure 2A,B). In contrast, non-RGCs were characterized as a mix of type-C (Ascl1 $\left.1^{+}, 50 \%\right)$ and type-A $\left(\mathrm{Dcx}^{+}, 50 \%\right)$ progenitors (Figure 2A,B). Approximately half of the non-RGCs were proliferating, as indicated by expression of Ki67 (Figure 2B). Those proliferating cells were mostly Ascl $1^{+}$type-C cells ( $60 \%$, Figure $2 \mathrm{C}$, 

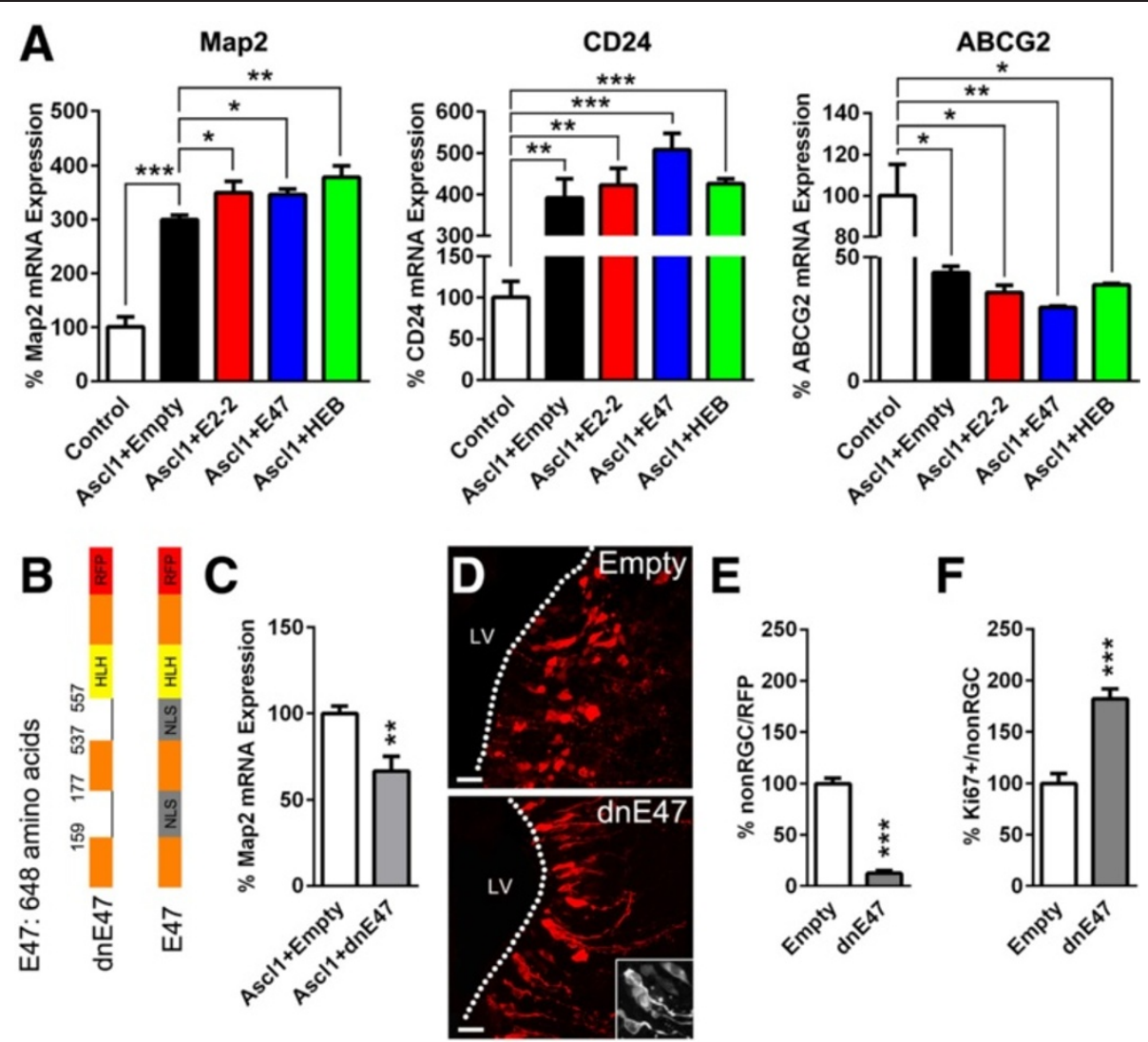

Figure 1 In vitro and in vivo modulation of bHLH function regulates neurogenesis. (A) Ascl1 nucleofection in NS5 cells caused an increased Map2 and CD24 expression whilst conversely decreasing ABCG2 mRNA expression, as detected via RT-qPCR (100 \pm 19.1 vs. $299.4 \pm 8.4,100 \pm 19.6$ vs. $392.1 \pm 46.1,100 \pm 15.2$ vs. $43.8 \pm 2.5$, respectively). Additionally, all E-proteins (E2-2, E47, HEB) further potentiated Ascl1-induced alteration in marker expression, when co-nucleofected with Ascl1 (Map2: $299.4 \pm 8.4$ vs. $349 \pm 21.2,345.7 \pm 10,378.3 \pm 21$; CD24: $392.1 \pm 46.1$ vs. $423.3 \pm 39.7$, $508.5 \pm 40.2,426.4 \pm 11.7 ; A B C G 2: 43.8 \pm 2.5$ vs. $35.7 \pm 2.9,29.7 \pm 0.5,38.8 \pm 0.6$, respectively). (B) Schematic illustration of the dominant-negative construct of $E 47$ ( $d n E 47)$, where the nuclear localization sequence is missing, therefore preventing its nuclear translocation and transcriptional activity of its dimerizing partners (F, insert). (C) Co-nucleofection of $d n E 47$ reduced Ascl1-induced neurogenesis as revealed by Map2 RT-qPCR measurements (100 \pm 4.2 vs. $66.8 \pm 8.5$ ). (D, E) Targeted in vivo electroporation of the dnE47-RFP construct rapidly reduced RGC differentiation, as revealed by the lower proportion of non-RGCs, when compared to an empty RFP control plasmid (100 $\pm 5.5 \mathrm{vs.} 12.6 \pm 2.7) 2$ days post-electroporation. (F) Cycling progenitors (non-RGC) were maintained proliferating (Ki67 ${ }^{+}$) following $d n E 47$ induction (100 \pm 9.6 vs. 182 \pm 9.6$) . P$ values: ${ }^{*} P<0.05$; ${ }^{* *} P<0.01 ;{ }^{* *} P<0.001$. All quantifications were normalized to control conditions. Scale bars: D, $20 \mu \mathrm{m}$.

Additional file 1C), while only $\sim 25 \%$ expressed the type-A cell marker Dcx (Figure 2C, Additional file 1D). Interestingly, $\sim 10 \%$ of proliferating non-RGCs exhibited a transitory phenotype between type- $\mathrm{C}$ and type-A cell stages and were positive for both markers $\left(\mathrm{Ascl}^{+} \mathrm{Dcx}^{+}\right.$; Figure 2C).

We next confirmed the blockade of RGC differentiation after ectopic $d n E 47$ using these antigenic criteria. Overexpression of $d n E 47$ resulted in an increase in the number of Vimentin ${ }^{+} / \mathrm{RFP}^{+}$cells (Figure 2D, Additional file $1 \mathrm{E}$ ), whilst the numbers of $\mathrm{Ascl}^{+} / \mathrm{RFP}^{+}$(type-C) and $\mathrm{Dcx}^{+} / \mathrm{RFP}^{+}$(type-A) precursors were concomitantly decreased at 2 dpe compared to controls (Figure 2E,F, Additional file 1F,G). Strikingly, the retention of a more immature phenotype by the electroporated cells was further supported by the 3-fold increase of $\mathrm{Dcx}^{+}$cells, still expressing type-C cell specific Ascl1 (Figure 2G).

Altogether, these experiments demonstrate that the progression of RGC differentiation can be analyzed based on morphological criteria and reveal a dependence of NSC differentiation on Class I/II bHLH transcriptional activity in the postnatal SVZ.

\section{E-proteins exhibit a complex spatio-temporal pattern of expression in the postnatal forebrain}

Based on these findings, we further explored both spatial and temporal E-protein expression in the postnatal and adult forebrain. We first analyzed the spatial pattern of expression by in situ hybridization (ISH) at postnatal day 6 (P6) and 60 (P60). All three genes coding for E-proteins 


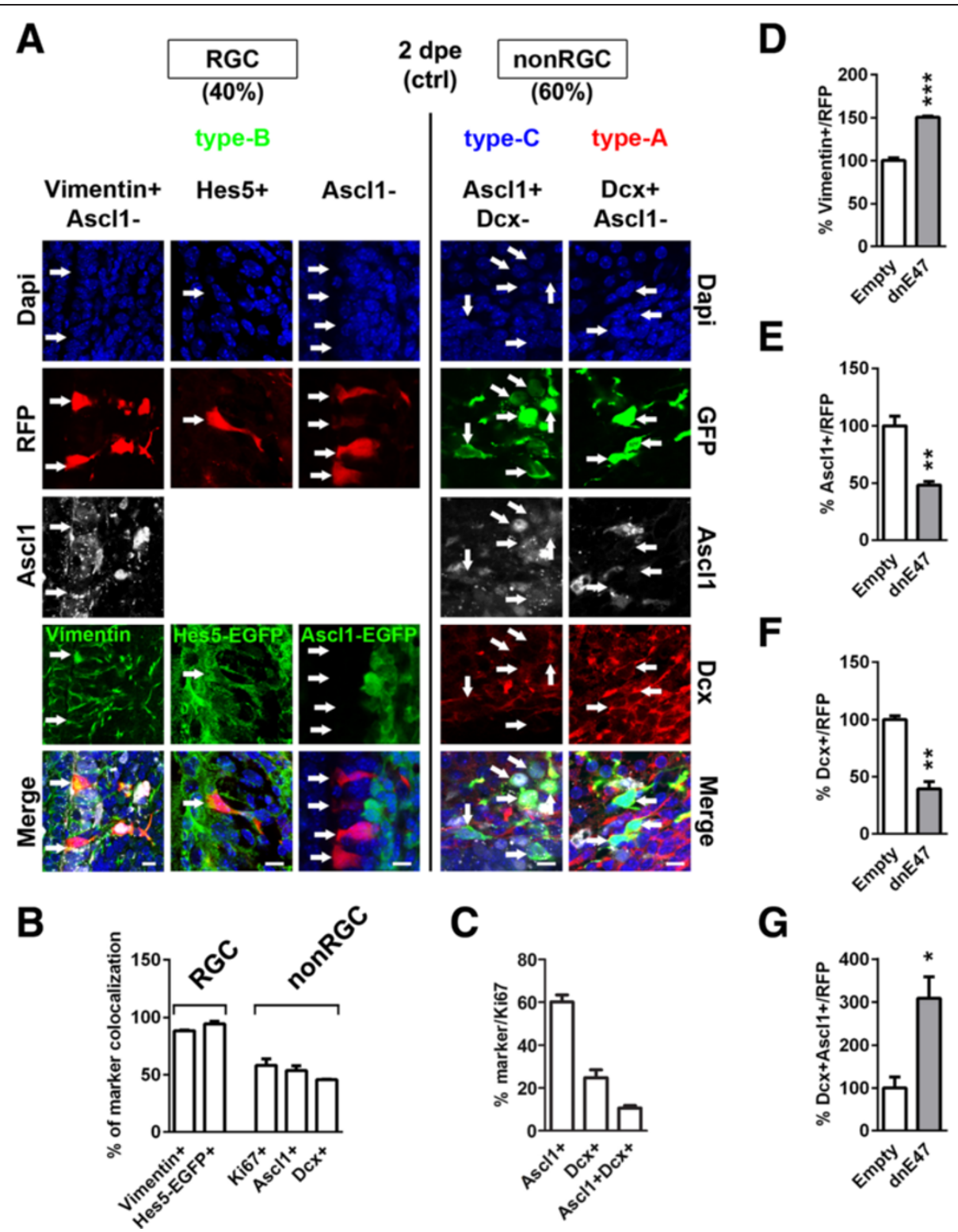

Figure 2 Antigenic properties of radial glial as well as non-radial glial cells and confirmation of differentiation blockade by $d n E 47$ overexpression. (A, B), At 2 days post electroporation (dpe), 40\% of the labeled cells showed morphological criteria of radial glial cells (RGCs, i.e., bipolar processes, apical connection to lateral ventricle (LV) lumen), while 60\% presenting a spherical morphology were distant from the LV and were defined as non-RGCs. Morphologically-defined RGCs express the NSC marker Vimentin (88.4 \pm 0.7) and were EGFP positive in Hes5-EGFP reporter mice (94.2 \pm 2.4 ), but negative in Ascl1-EGFP reporter mice, in which type-B or type-C cells are labelled, respectively [33,34]. In contrast, non-RGCs consisted of a heterogeneous population of type-C (i.e., Ascl1 ${ }^{+}, 53.6 \pm 4.3$ ) and type-A cells (i.e., Dcx $\left.{ }^{+}, 45.9 \pm 0.2\right)$. Non-RGCs were frequently proliferative (i.e., Ki67 $7^{+}, 58.2 \pm 5.7$ ). (C) A subsequent characterization of cycling non-RGCs revealed that most Ki67 ${ }^{+}$cells were type-C cells $\left(\mathrm{Ascl}^{+}, 60.1 \pm 4.4\right)$, whereas fewer were type-A cells $\left(\mathrm{Dcx}^{+}, 22.9 \pm 4.0\right)$. Notably, a minor population of cycling cells were double-positive for Ascl1 and Dcx (10.1 \pm 1.4 ), probably representing a transition phase in between type-C and type-A phenotypes. (D-G) Antigenic assessment of RGC differentiation blockade following dnE47 overexpression. Electroporation of dnE47 in the postnatal SVZ reduced RGC differentiation, as revealed by the increased number of Vimentin ${ }^{+} /$RFP $^{+}$RGCS (D) and concomitant decrease of Ascl1 $1^{+} / \mathrm{RFP}^{+}$(E) and Dcx $/ \mathrm{RFP}^{+}$(F) non-RGCs, respectively, when compared to an empty RFP control plasmid 2 dpe (Vimentin: $100 \pm 3.2$ vs. $150.5 \pm 1.6$; Ascl1: $100 \pm 8.4$ vs. $48.2 \pm 3.1$; Dcx: $100 \pm 3.3$ vs. $39.5 \pm 6.3$ ). This blockade of differentiation was further supported by an increase in Dcx ${ }^{+} / \mathrm{RFP}^{+}$type-A cells retaining expression of the type-C cell marker Ascl1 (Dcx ${ }^{+} A s c 11^{+}, 100 \pm 25.7$ vs. $\left.308.5 \pm 50.3\right)(G) . P$ values: ${ }^{*} P<0.05 ;{ }^{* *} P<0.01 ;{ }^{* * *} P<0.001$. Quantifications were normalized to control conditions (D-G). Scale bars: $\mathbf{A}, 10 \mu \mathrm{m}$. 
(E2-2, E2A, and $H E B)$ were abundant in the postnatal forebrain and were enriched in germinal zones, i.e., dentate gyrus, SVZ, and RMS at P6 (Figure 3A,B). These results were confirmed by real-time quantitative polymerase chain reaction (RT-qPCR) measurement from the microdissected lateral SVZ and adjacent parenchyma (i.e., striatum). All E-protein transcripts were enriched in the SVZ, with a clear predominance of $E 2$ 2 and E2A (Figure 3C). At P60, E-protein transcripts were generally less abundant compared to earlier postnatal ages. While E2-2 expression was still enhanced in the SVZ and the RMS, E2A and $H E B$ expression levels were only marginally higher than in non-germinal regions (Figure 3A,B), thus implying that E2-2 may be required for neuronal differentiation continually during development and into adulthood.

Having demonstrated an enrichment of E-protein transcripts in germinal regions of the postnatal forebrain, regulation during early neuronal differentiation was assessed. In vitro differentiation of the NS5 cell line increased the expression of all E-protein transcripts. Upregulation of E2-2 and $H E B$ had occurred following $24 \mathrm{~h}$, before any increase of doublecortin $(D c x)$, a neuronal differentiation marker, could be detected. After $48 \mathrm{~h}$ of differentiation, all E-protein transcripts were significantly upregulated (Figure 3D).

A similar upregulation was observed in vivo. Early progenitors and committed neuroblasts were isolated based
A
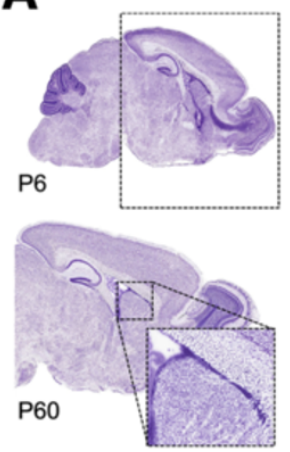

B

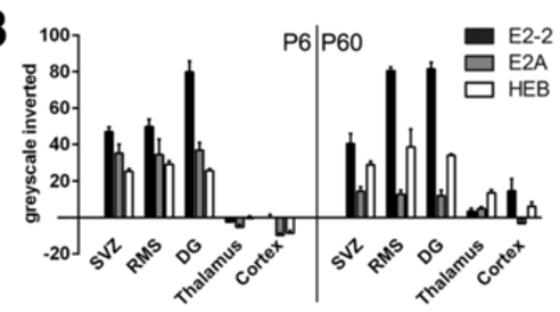

E2-2
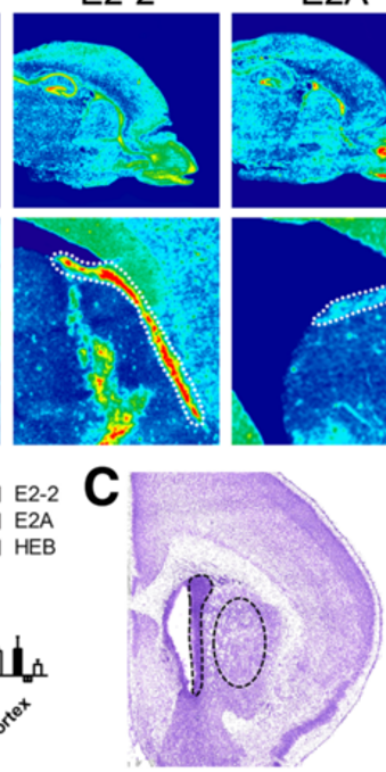

$E 2 A$
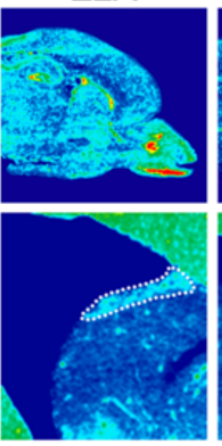
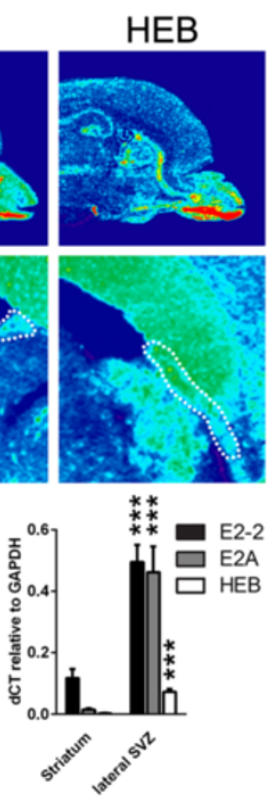

E

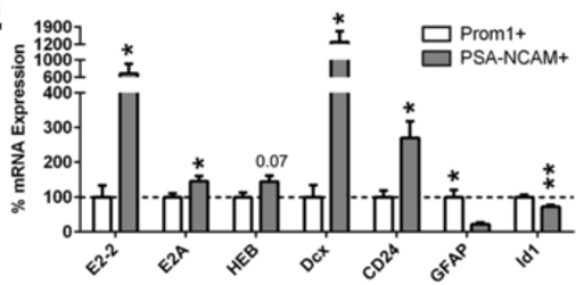

Figure 3 E-protein mRNA expression is enriched in germinal regions of the postnatal and adult forebrain and is increased during NSC differentiation in vitro and in vivo. (A) ISH of E2-2, E2A, and HEB revealed its enhanced expression in the SVZ (dashed zone at P60), the RMS, and the dentate gyrus, when compared to non-neurogenic regions (i.e., thalamus, cortex) at P6 as well as P60. (B) Inverted greyscale quantification of A. (C) E2-2, E2A, and HEB transcripts were highly expressed in the lateral SVZ compared to the striatum (dashed zone circling both regions) (0.18 \pm 0.03 vs. $0.5 \pm 0.06,0.02 \pm 0.004$ vs. $0.46 \pm 0.08,0.003 \pm 0.0004$ vs. $0.07 \pm 0.01$, respectively). (D) Upon differentiation, E-protein mRNA levels were upregulated in NS5 cells (two-way ANOVA followed by Dunnett's post hoc test). Differentiation progress was confirmed by upregulation of doublecortin (DCX) transcripts, an early neuronal marker, and normalized to GAPDH and shown as a percentage vs. D0. (E) E-protein transcription, in particular E2-2, was enhanced in more mature PSA-NCAM ${ }^{+}$MAC sorted neuroblasts compared to earlier Prominin $-1^{+}$(or CD $133^{+}$) NSCs/progenitors $(100 \pm 32.0$ vs. $687.8 \pm 226.4,100 \pm 9.9$ vs. $145.4 \pm 15.4,100 \pm 12.1$ vs. $144.0 \pm 17.4$, respectively). Cell sorting efficiency was confirmed by enrichment of $D c x$ $(100 \pm 34.0$ vs. $1291.3 \pm 438.6)$ and CD24 (100 \pm 17.8 vs. $270.1 \pm 48.1)$ transcripts in neuroblasts, while the generic NSC transcripts GFAP (100 \pm 20.4 vs. $22.1 \pm 4.5)$ and $l d l(100 \pm 6.5$ vs. $72.8 \pm 4.7)$ were enriched within Prominin $-1^{+}$sorted cells. $P$ values: ${ }^{*} P<0.05 ;{ }^{*} P<0.01$; ${ }^{* *} P<0.001$. All quantifications were normalized to control conditions (D, E). 
on their differential expression of the cell surface markers Prominin-1 and PSA-NCAM, respectively. Measurements of cell-specific markers confirmed the efficiency of the approach by showing that Prominin- $1^{+}$sorted cells were enriched for the stem cell markers GFAP and Id1, while $D c x$ and $C D 24$ enrichment was prominent in PSA-NCAM ${ }^{+}$ sorted cells. Measurements of E-protein transcripts by RT-qPCR revealed that $E 2-2$ and, to a lesser extent, $E 2 A$ and $H E B$, were strongly upregulated in the postnatal SVZ during NSCs differentiation (Figure 3E).

Altogether, our results indicate that E-protein expression is spatially and temporally regulated in a pattern that matches NSC differentiation during postnatal forebrain development.

\section{E-protein manipulation alters the progression of NSC differentiation in the postnatal SVZ}

We next performed further E-protein gain-of-function (GoF) and loss-of-function (LoF) experiments in the postnatal lateral SVZ, by means of plasmid electroporation (as above) (Figure 4A). We focused this functional characterization onto E2-2, which appears to be the most prominent E-protein expressed in the postnatal and adult SVZ (see above), and E2A, which is the best studied Eprotein in CNS development [23,25,29,35-37].

GoF experiments resulted in the rapid transformation of RGCs into non-RGCs. Thus, whilst E2-2 and E2A overexpression increased the transformation of RGCs into non-RGCs by $30 \%$ and $40 \%$, respectively, both $E 2-2$ and $E 2 A$ silencing decreased it by $20 \%$ (Figure $4 \mathrm{~B}, \mathrm{C}$, Additional file $1 \mathrm{H}$ ). We next focused our analysis on non-RGCs, which, at this early timepoint ( $2 \mathrm{dpe})$, consisted of transient amplifying progenitors (type-C) and neuroblasts (type-A) (Figure 2A,B). E-protein overexpression significantly reduced the proliferation of non-RGCs, as demonstrated by a $\sim 45 \%$ decrease in the number of green fluorescence protein positive $\left(\mathrm{GFP}^{+}\right)$non-RGCs expressing the cell cycle marker Ki67. In contrast, LoF enhanced the proliferation capacity of non-RGCs (Figure 4D). Interestingly, these effects were more pronounced following E2-2 silencing, consistent with its higher expression in the postnatal SVZ compared to $E 2 A$ (see above).

Altogether, these data are in agreement with the results obtained with the $d n E 47$ construct (Figure $1 \mathrm{D}-\mathrm{F}$ ) and suggest that E-proteins control the differentiation of NSCs, and influence the cycling behavior of their progeny.

We next tested whether the changes in proliferation observed following E-protein GoF could be explained by cell cycle exit induction. Dividing cells in S-phase that incorporated 5-ethynyl-2'-deoxyuridine (EdU) $24 \mathrm{~h}$ prior to sacrifice, but did not re-enter another round of cell division (i.e., cell cycle exit), would no longer express Ki67. We quantified the number of $\mathrm{EdU}^{+} \mathrm{Ki}^{-} / \mathrm{EdU}^{+}$ cells and found a doubling in the number of progenitors that had exited the cell cycle, when E2-2 was overexpressed (Figure 5A), whereas a smaller number of progenitors exited the cell cycle upon E2-2 silencing (Figure 5B). Finally, we tested whether E2-2-induced cell cycle exit resulted in an abortive differentiation or whether cells appropriately completed their differentiation into $\mathrm{Dcx}^{+}$neuroblasts. We observed a $\sim 30 \%$ increase of $\mathrm{Dcx}^{+}$ neuroblasts (type-A) within the postnatal forebrain at 2 dpe (Figure 5C, Additional file 1I), which paralleled the reduction of the number of RGCs described above, whereas the number of $\mathrm{Ascl}^{+}$type-C cells remained unaltered (Figure 5D, Additional file 1J).

Taken together, these results highlight an important role of E-proteins in controlling the timing and progression of NSC differentiation in the postnatal SVZ. Thus, upon E2-2 overexpression, a concomitant decrease of type-B RGCs and increase of $\mathrm{Dcx}^{+}$type-A cells was observed. These observations, together with the stable number of $\mathrm{Ascl}^{+}$type-C cells, suggest a more rapid differentiation of E2-2 overexpressing cells as schematized in Figure 5E,F.

\section{E47 disruption is not sufficient to mediate the switch of Ascl1-dependent transcription}

E-proteins induce NSC differentiation by transactivation of bHLH proneural proteins. Among those is Ascl1, expressed mainly by progenitor cells in the postnatal forebrain $[19,38]$. We confirmed the interdependence of E-proteins and Ascl1 by NSC differentiation induction, combining GoF and LoF experiments in isolated progenitors in vitro. Ascl1 knock-down resulted in a complete loss of Map2 mRNA transcription, when E2-2 or E47 were concomitantly overexpressed. This confirms that E-protein activity is largely dependent on Ascl1 expression. On the other hand, Ascl1 is still able to exert its function although to a lesser extent upon silencing of $E 2-2$, but not after silencing $E 2 A$, illustrating both redundancy but also a strong dependency on E2A expression in SVZ-derived progenitor cells (Figure 6A).

The bHLH protein Ascl1 has recently been shown to control proliferation and differentiation in neural progenitors by sequentially activating cell cycle progression and cell cycle arrest genes in a context-dependent manner [22]. Therefore, we next assessed whether modifications in E-protein expression levels that occur during neural progenitor cell differentiation could mediate this molecular switch. $E 2 A$, in the form of $E 47$, known to be the main E-protein binding to Ascl1 [21], was overexpressed or silenced in isolated neurosphere cultures and the level of expression of Ascl1 targets, reported to be differentially expressed during cell cycle progression (FoxM1, Cdk4) and cell cycle arrest (Gadd45g, Ccng2, Btg2, Prmt2) [22], was measured by RT-qPCR. No consistent change in expression of genes differentially 

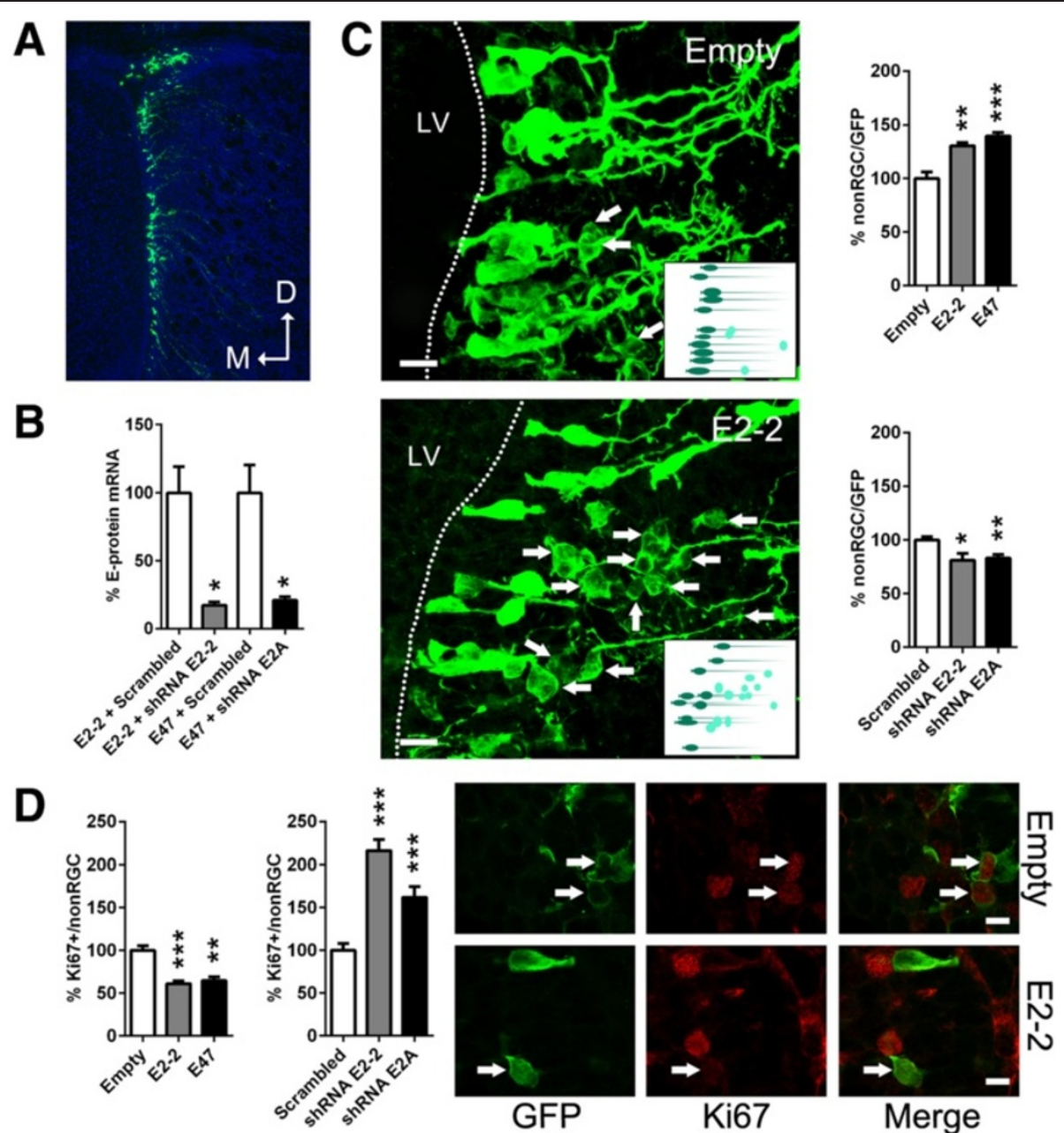

Figure 4 E2-2 and E2A sequentially affect RGC differentiation and progenitor proliferation. (A) Representative illustration of a green fluorescence protein (GFP) plasmid electroporation into the lateral wall of the LV. (B) In vitro characterization of the shRNAs used in this study. shRNA against E2-2 or E2A decreased E2-2 or E2A expression (100 \pm 18.9 vs. $17.2 \pm 2.4$ or $100 \pm 20.2$ vs. $20.9 \pm 2.5$, respectively) within neurosphere cultures, when co-nucleofected with E2-2 or E47 overexpression plasmids, respectively. (C) E2-2 and E47 overexpression constructs increased transition from RGCs (bipolar processes, apical connection to LV lumen) to non-RGCs (no processes, spherical morphologies, distant from the LV wall) at 2 dpe (100 \pm 3.9 vs. $130.5 \pm 3.0$ or $139.7 \pm 1.4$, respectively). When shRNA plasmids against E2-2 or E2A were applied, most electroporated cells maintained a RGC morphology, as reflected by the reduced ratio of non-RGC cells compared to control conditions (100 \pm 3 vs. $81 \pm 6.4$ or $82.9 \pm 3.6$, respectively). Confocal micrographs illustrate RGCs and non-RGCs coexisting in the neurogenic niche. Inserts show a schematic view of the RGC to non-RGC transition. (D) E2-2 and E47 overexpression constructs decreased Ki67 immunoreactivity within progenitors (non-RGC) at 2 dpe $(100 \pm 5.6$ vs. $61 \pm 3.5$ or $64.7 \pm 4.1$, respectively). shRNA constructs against E2-2 and E2A-induced opposite effects (100 \pm 8 Vs. $216 \pm 13.2$ or $161.9 \pm 12.7$, respectively). Confocal micrographs illustrate representative non-RGCs positive or negative for Ki67, respectively. $P$ values: ${ }^{*} P<0.05$; ${ }^{* *} P<0.01$; ${ }^{* *} P<0.001$. All quantifications were normalized to control conditions. Scale bars: $\mathbf{C}, 20 \mu \mathrm{m} ; \mathbf{D}, 10 \mu \mathrm{m}$.

targeted by Ascl1 was detected following $E 2 A$ GoF or LoF (Figure 6B).

In summary, the divergent context-dependent function of Ascl1 in promoting cell proliferation and in triggering differentiation, as described recently [22], is apparently independent of E-protein activity. Rather, these findings propose that E-protein upregulation during NSC differentiation is likely to act in parallel with other signaling pathways to fine-tune differentiation progression in an Ascl1-dependent manner [39].

\section{Discussion}

In the present study, we demonstrate enriched expression of E-proteins in postnatal germinal regions of the murine forebrain and highlight their key role as transcriptional orchestrators of postnatal SVZ neurogenesis.

bHLH family members are known to regulate a variety of developmental programs in several tissues of the organism, such as myogenesis, hematopoiesis, and pancreatic and heart development, as well as neurogenesis [5]. In the CNS, proneural Class II proteins are the most studied 


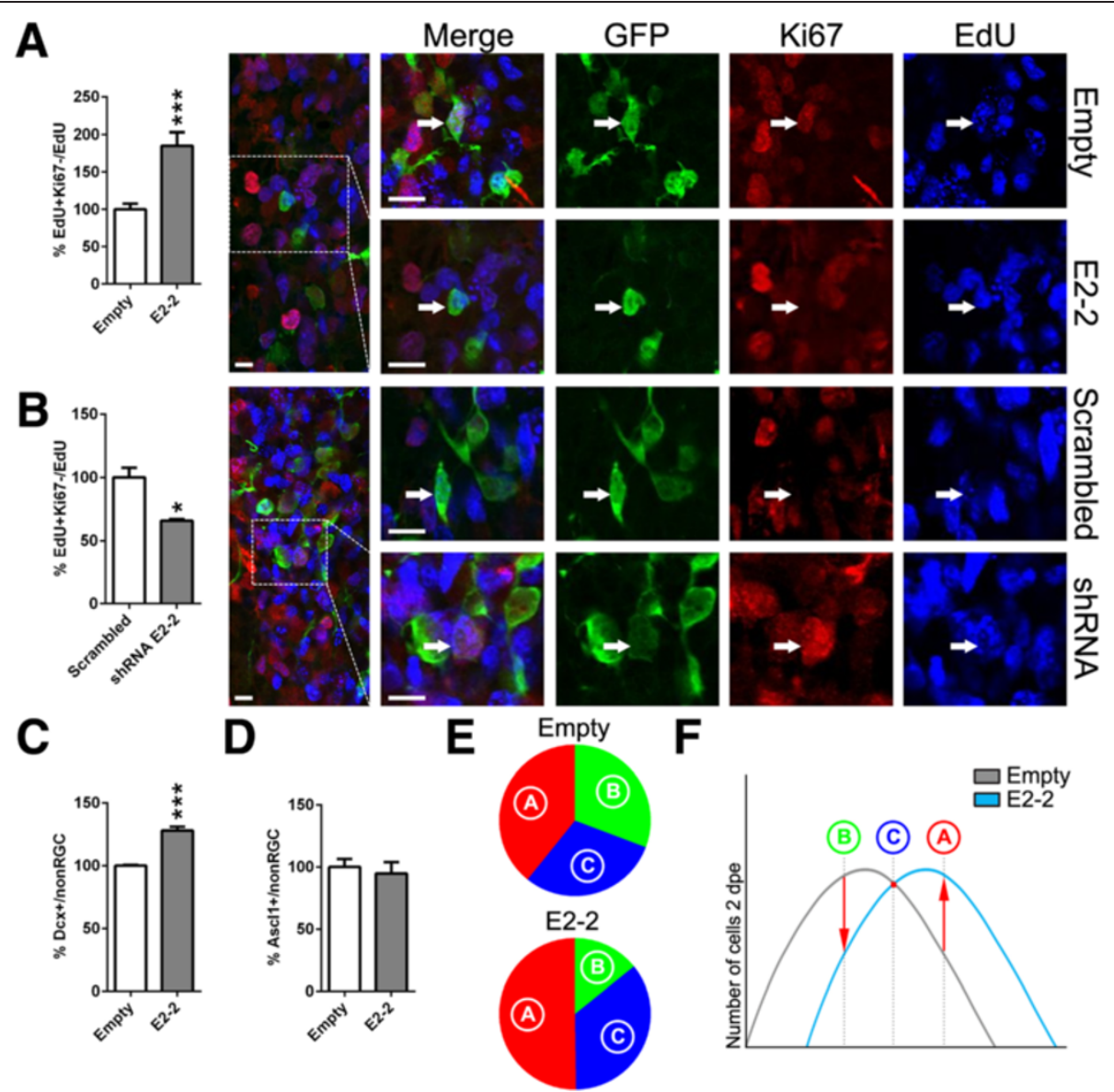

Figure 5 E2-2 alteration influences cell cycle exit of progenitors in vivo. (A) E2-2 overexpression increased cell cycle exit (EdU ${ }^{+} K i 67^{-} / E d U^{+}$) among the progenitor cell population (non-RGC) compared to control conditions at 2 dpe (100 \pm 7.5 vs. 184.9 \pm 18.0 ). Confocal micrographs show representative non-RGCs $\left(\mathrm{GFP}^{+}\right)$having cycled within $24 \mathrm{~h}$ prior to sacrifice $\left(\mathrm{EdU}^{+}\right)$and having re-engaged $\left(\mathrm{Ki} 67^{+}\right)$or exited the cell cycle $\left(\mathrm{Ki} 67^{-}\right)$, respectively. (B) In contrast, knock-down of E2-2 decreased cell cycle exit within the progenitor pool as illustrated by the increased Ki67 immunoreactivity among EdU ${ }^{+}$non-RGCs, when compared to control conditions (Scrambled) (100 \pm 7.8 vs. $\left.65.8 \pm 1.3\right)$. (C, D) E2-2 overexpression also increased the number of Dcx ${ }^{+}$neuroblasts (100 \pm 0.5 vs. $\left.128.1 \pm 2.9\right)$ (C), whereas the number of Ascl $1^{+}$type-C cells remained unchanged (100 \pm 6.4 vs. $\left.94.6 \pm 9.2\right)$ (D). (E) Percentage of cell type composition (i.e., type-B $=R G C$, type-C $=A s c 11^{+}$, type-A $=D c x^{+}$) upon $E 2-2$ overexpression, when compared to an empty control plasmid at 2 dpe ( $30.7 \pm 4.6$ vs. $14.2 \pm 2.3,30.0 \pm 1.2$ vs. $35.6 \pm 2.5,39.2 \pm 0.3$ vs. $50.2 \pm 1.8$, respectively). (F) Summary model: E2-2 orchestrates neurogenesis progression within the murine forebrain. $P$ values: ${ }^{*} P<0.05 ;{ }^{* *} P<0.01 ;{ }^{* *} P<0.001$. Quantifications were normalized to control conditions (A-D). Scale bars: $\mathbf{A} \& \mathbf{B}, 20 \mu \mathrm{m}$.

members of the bHLH family. They were shown to be indispensable and sufficient to induce neurogenesis in drosophila [40], C. elegans [41,42], and mice [43]. During telencephalic development, Neurog2 and Ascl1 confer an opposing dorso-ventral expression gradient to specify distinct neuronal populations [44].

However, less is known regarding Class I bHLH protein expression patterns and their role during neurogenesis. In drosophila, Daughterless (E-protein homolog) knock-out results in defective precursor differentiation $[45,46]$. In contrast, deletion of single Class I bHLH protein members in rodents led to no gross anatomical phenotype [26] or spatially restricted developmental deficits [47]. Deletion of multiple E-proteins resulted in stronger phenotypes highlighting some degree of redundancy in between these genes [26]. Our co-expression experiments confirmed the potential interchangeability of E-proteins, since $E 2-2$, $E 47$, and $H E B$ were equally potent in transactivating Ascl1, even though the LoF analysis revealed Ascl1 to preferentially bind E47. Sequence analysis studies revealed extremely high sequence conservation within, as well as beyond, the HLH domains supporting possible redundancy among individual E-proteins [23]. Indeed, functional replacement of the mouse $E 2 A$ gene with an $E 2 A$ promoterdriven human $H E B$ cDNA rescued B-cell commitment and differentiation during B-lymphopoiesis [37].

Furthermore, expression studies have proposed a regulation of E-protein transcription during development, with a gradual restriction to germinal regions in the CNS [25], supporting key neurogenesis functions. Our ISH combined 


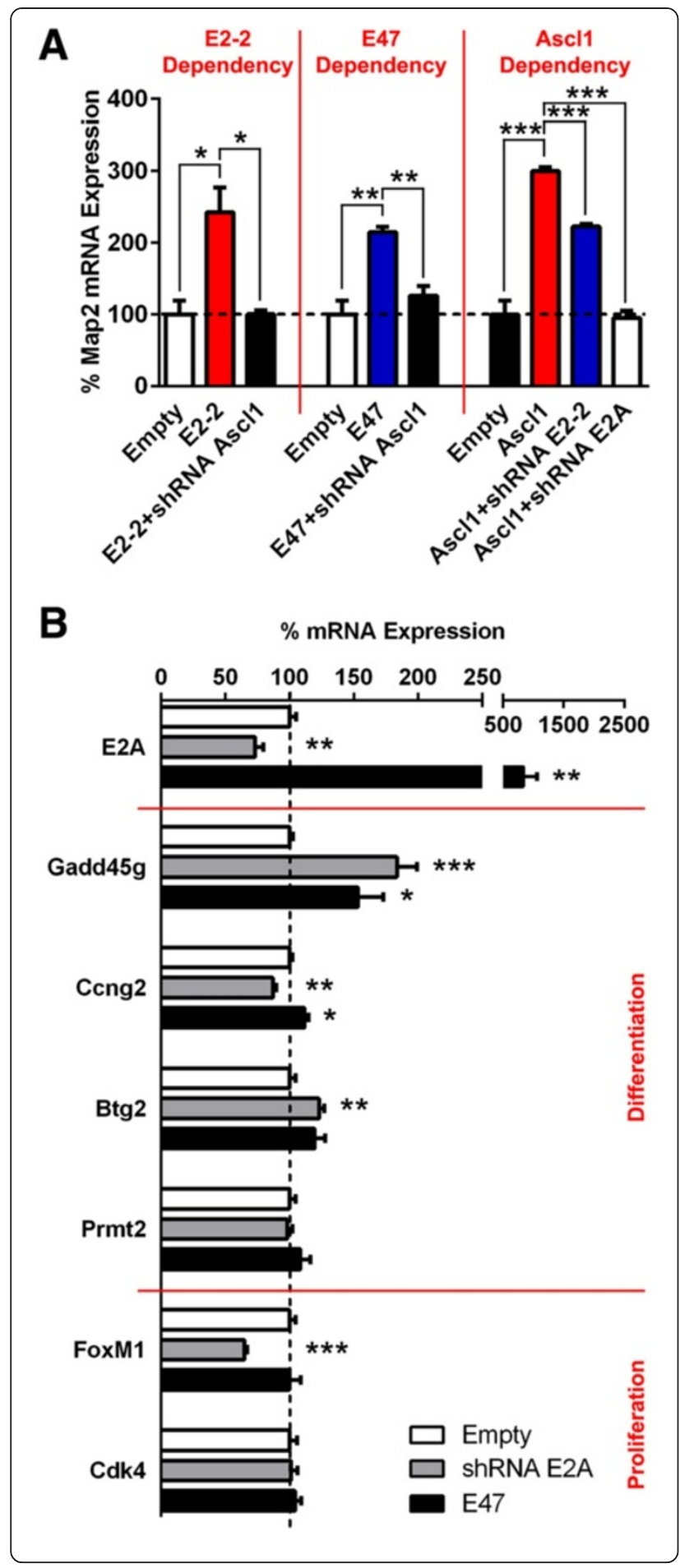

Figure 6 E47 fails to trigger Ascl1 to switch from proliferation to differentiation target genes. (A) Map2 mRNA expression was elevated when Ascll was overexpressed in isolated neurospheres in vitro (100 \pm 19.1 vs. $299.4 \pm 5.8)$. Concomitant knock-down of E2-2 or E2A using shRNA, respectively, reduced or abolished Ascl1-dependent Map2 expression ( $299.4 \pm 5.8$ vs. $222.2 \pm 3.7$ or $94.9 \pm 9.8$, respectively). More strikingly, Ascl1 silencing decreased Map2 expression level to control conditions, when E2-2 ( $100 \pm 19.1$ vs. $242.4 \pm 34.2$, $242.4 \pm 34.2$ vs. $100.3 \pm 4.9)$ or $E 47(100 \pm 19.1$ vs. $214.6 \pm 7.1,214.6 \pm 7.1$ vs. $125.7 \pm 13.6$ ) was overexpressed. (B) Although significant expression changes could be detected, E-protein gain-of-function did not systematically promote activation of Ascl 1 target genes mediating cell cycle arrest. Inversely, E-protein silencing did not activate Ascl1 target genes mediating cell cycle progression. $P$ values: ${ }^{*} P<0.05$; ${ }^{*} P<0.01 ;{ }^{* *} P<0.001$. All quantifications were normalized to control conditions.

with RT-qPCR gene expression analysis confirmed an enrichment of all E-protein transcripts in postnatal and adult germinal regions of the forebrain when compared to non-neurogenic regions. Notably, these expression experiments uncovered E2-2 as the most abundant E-protein in the SVZ, followed by a less prominent expression for $E 2 A$ and $H E B$. Additionally, E-proteins seem not only to be restricted spatially but also temporally during lineage progression. More differentiated progenitors exhibited increased transcription levels in vitro as well as in vivo, further implicating a specialized function in maintaining proper neurogenesis behavior. Altogether, these results highlight a complex regulation of E-protein expression in germinal regions of the postnatal forebrain.

The dramatic blockade of NSC differentiation and subsequent neurogenesis observed following $d n E 47$ overexpression in vitro as well as in vivo underlines the importance of a functional bHLH network for lineage progression. Based on these findings, we further aimed at manipulating E-protein expression more concisely in the lateral SVZ using overexpression and shRNA plasmids within an established postnatal electroporation approach [31,32]. Major alterations in progenitor proliferation and cell cycle exit were evident. These results are in agreement with a previously described role of E2A in cell cycle regulation in transiently transfected NIH3T3 fibroblasts, by activating cyclin-dependent kinase inhibitors $[27,48,49]$. Moreover, Id proteins, known E-protein antagonists (see above), enhance cell cycle duration and prevent cell cycle exit, which was further confirmed with a decreased cyclinD1 and increased $p 27^{K i p 1}$ (cyclin-dependent kinase inhibitor 1B) expression within the VZ of triple knock-out mice [18]. In line with Id protein mediated anchorage to the neurogenic niche [18], E-proteins were also reported to actively repress expression of E-cadherin, a cell adhesion molecule $[50,51]$. Recent studies in drosophila, revealing a direct transcriptional regulation of Emc (Id protein homolog) by Daughterless, coupled 
with the physical sequestration of E-proteins by Class $\mathrm{V}$ bHLH members [6], results in an autoregulatory feedback [24,52]. In addition, E-protein expression and therefore lineage progression seems to be initially mediated by extracellular signaling pathways, which is consistent with earlier reports, suggesting a general role for Shh and BMPs in SVZ neurogenesis [53-55]. In drosophila, it was demonstrated that Hh (Shh homolog) and Dpp (BMP homolog) specifically repress Id expression and thus increase Eprotein activity [24], ultimately leading to germinal niche detachment and altered cell cycle behavior.

Our findings suggest that the effects of E-proteins on SVZ NSC differentiation are entirely dependent on Ascl1, which is expressed in all postnatal SVZ progenitors [19,56]. Knock-down of Ascl1 entirely abrogated the proneural activity of $E 2-2$ and $E 2 A$, demonstrating that E-proteins converge with the same Class II bHLH protein. The incomplete loss of Ascl1 activity when E2-2 is silenced is likely due to a persistent endogenous E47 activity, as Ascl1 seems to rely more on $E 2 A$ than on E2-2, demonstrated by the absence of Ascl1 activity upon $E 2 A$ silencing. Recent findings propose that sustained Ascl1 expression favors cell differentiation, whereas oscillatory expression correlates more with proliferative cell fates [57]. Given that E-proteins, in competition with Id proteins, tightly regulate Ascl1 protein stability [58] and that Ascl1 has lately been demonstrated to target two subsets of genes, namely proliferation- and differentiation-associated genes [22], we investigated a role for E-proteins in mediating this switch in binding bias. However, in the present study, E2A alterations did not induce directed and systematic gene expression changes, at least for the Ascl1 target genes tested, most likely mitigating the probability of E-proteins to induce differentiation through promoting Ascl1 binding and activation of cell cycle arrest genes. This implies that E-proteins are likely to operate in parallel with other signaling pathways to fine tune differentiation progression in an Ascl1-dependent manner [39].

Although our results did not reveal significant differences in the expression pattern of distinct E-proteins during postnatal SVZ neurogenesis, and suggest an interchangeability of E-proteins in the context of Ascl1induced SVZ NSC differentiation, it should be noted that the dimerization properties of bHLH proteins can be affected at the post-translational level. For example, GSK3 $\beta$ phosphorylation of Neurog2 was described to influence its dimerization with E47 in the developing cortex, thereby affecting its transcriptional activity [59]. Similar mechanisms might be at play in the postnatal SVZ to fine tune the choice of proneural/E-protein-binding partners and regulate individual aspects of NSC differentiation, such as, for example, specification. Previous studies have indeed demonstrated a specific role of E2-2 for the generation of a unique subset of neural progenitors during pontine development [47], despite the presence of other E-proteins. Also, B- and T-lymphocyte specification was shown to be orchestrated by E2A and HEB $[60,61]$. Whether Class I/II bHLH protein dimerization is dynamically regulated in the postnatal SVZ to influence fate specification is currently unknown and will be the subject of future investigations. Performing such experiments in the postnatal SVZ is particularly attracting due to the regional expression of some proneural proteins as, for example, Neurog2, which shows dorsal enrichment in the postnatal SVZ in a population that gives rise to glutamatergic neurons $[62,63]$.

\section{Conclusions}

In the present work, we demonstrate a diverse expression pattern of Class I bHLH proteins and underpin their underestimated significance in orchestrating early neuronal lineage progression. However, the precise mechanism behind E-proteins regulating NSC differentiation remains to be elucidated, but is unlikely to rely solely on Ascl1 heterodimerization.

\section{Methods}

\section{Cell culture and in vitro nucleofection}

The mouse embryo-derived and immortalized RGC line NS5 was cultured as described earlier [28] and was nucleofected following the manufacturer's instructions using a 4D-nucleofector device with SG solution (Lonza, Basel, Switzerland) and the EN150 program with a maximum of $0.5 \mu \mathrm{g}$ of plasmid DNA per $1 \times 10^{6}$ cells. NS5 cell differentiation was achieved by plating cells into polyornithin-coated $\left(0.001 \%\right.$ in $\mathrm{H}_{2} \mathrm{O}$, Sigma-Aldrich, St. Louis, MO, USA) and laminin-coated $\left(20 \mu \mathrm{g} / \mathrm{mL}\right.$ in $\mathrm{H}_{2} \mathrm{O}$, Life Technologies, Carlsbad, CA, USA) flasks in D1 medium (Euromed-N stem cell medium; Lucerna Chem, Lucerne, Switzerland) supplemented with $1 \%$ penicillin/ streptomycin, 0.25\% L-glutamine, 1\% B27 (Life Technologies), $0.5 \% \mathrm{~N} 2$ (Life Technologies), and $5 \mathrm{ng} / \mathrm{mL}$ FGF2 (Peprotech, Hamburg, Germany) [64].

Neurosphere-forming progenitor cells were isolated from the SVZ of P4 aged animals. The SVZ was microdissected and the tissue digested with a solution of DNAse I (Worthington, Lakewood, NJ, USA), Papain (Worthington), and Dispase II (Roche, Basel, Switzerland), subsequently triturated and filtered through a $70 \mu \mathrm{m}$ cell strainer (BD Biosciences, Franklin Lakes, NJ, USA). Cells were plated into DMEM/F12 medium supplemented with $1 \%$ N2, EGF, FGF2 (both $20 \mathrm{ng} / \mathrm{mL}$, Peprotech), heparin $(1 \mu \mathrm{g} / \mathrm{mL})$, and $1 \%$ penicillin/streptomycin. For nucleofections, a mouse neural stem cell solution (Lonza), program DS113, and a maximum of $1 \mu \mathrm{g}$ of plasmid DNA per $1 \times 10^{6}$ cells were used.

Both NS5 and progenitor cells were subjected to RNA isolation and subsequent RT-qPCR 24 to $48 \mathrm{~h}$ post-nucleofection. 


\section{Animals and postnatal electroporation}

All animal experiments were performed in agreement with the Canton of Zurich veterinary office guidelines (authorization 182/2011). All mice used in this study were of the CD1 (Swiss mice) strain and were obtained from the Charles River laboratory.

Electroporation of RGCs lining the lateral ventricle was performed on postnatal-day-2 mice (P2), as described previously [31,32]. In brief, following anesthesia by hypothermia, P2 pups were injected with $2 \mu \mathrm{L}$ of plasmid solution $(5 \mu \mathrm{g} / \mu \mathrm{L}$ in PBS). Fast Green 1\% (Sigma-Aldrich) was used to assess accuracy of the intra-ventricular injections. Successfully injected mice were subjected to five electrical pulses ( $95 \mathrm{~V}, 50 \mathrm{~ms}$, separated by $950 \mathrm{~ms}$ intervals) using the ECM 830 BTX electroporator (Harvard Apparatus, Holliston, MA, USA) and tweezer electrodes (5 mm diameter; BTX Tweezertrodes, Harvard Apparatus) coated with conductive gel (Signa gel, Parker Laboratories, Fairfield, NJ, USA). For proliferation studies, $50 \mathrm{mg} / \mathrm{kg}$ 5-ethynyl-2'-deoxyuridine (EdU) were administered subcutaneously $24 \mathrm{~h}$ prior to sacrifice.

\section{Tissue processing}

Two days post-electroporation, mice were deeply anesthetized (150 mg/kg pentobarbital, i.p.) and transcardially perfused with Ringer solution supplemented with heparin ( $250 \mathrm{mg} / \mathrm{L}$, Sigma-Aldrich) followed by $4 \%$ paraformaldehyde (PFA) (Sigma-Aldrich). Then, $50 \mu \mathrm{m}$ thick vibratome sections (Leica, Wetzlar, Germany) were collected as a series of six encompassing the entire rostro-caudal extent of the lateral ventricle. Sections were stored at $-20^{\circ} \mathrm{C}$ in antifreeze solution (25\% Glycerol, 25\% Ethylenglycol and $50 \% 0.1 \mathrm{M} \mathrm{PB})$.

\section{Immunostaining}

All immunostainings were performed on a complete series of free-floating sections. Blocking and permeabilization were achieved by incubating the sections for $2 \mathrm{~h}$ in $0.1 \mathrm{M}$ PB supplemented with $0.4 \%$ Triton-X100 and a TNB buffer (thereafter mentioned as $0.4 \%$ TNB-TX100) consisting of $0.05 \%$ Casein (Sigma-Aldrich), 0.25\% bovine serum albumin (Sigma-Aldrich), and 0.25\% Topblock (Lubio Science, Lucerne, Switzerland) at room temperature. Afterwards, primary antibody incubations were performed in $0.4 \%$ TNB-TX100 at $4^{\circ} \mathrm{C}$ overnight ( $\mathrm{M} \alpha \mathrm{Ki} 67,1: 300$ (BD Biosciences); Rb $\alpha$ Ki67, 1:500 (MM France, Francheville, France); G $\alpha$ Dcx, 1:300 (Santa Cruz Biotechnology, Santa Cruz, CA, USA); Ch $\alpha$ Vimentin, 1:1000 (Millipore, Darmstadt, Germany); and M $\alpha$ Ascl1, 1:300 (BD Biosciences)). Then, incubation with species-matched secondary antibodies (Life Technologies) was performed for $2 \mathrm{~h}$ at $4^{\circ} \mathrm{C}$ in $0.4 \%$ TNB-TX100. GFP signal was amplified using a biotin-conjugated secondary antibody against the GFP primary antibody (Ch $\alpha$ GFP, 1:1,000 (Aves Labs, Tigard,
OR, USA)). In addition, the tissues were incubated for 15 min with a biotin-specific streptavidin Alexa 488 complex. Finally, sections were counterstained using 4',6-diamidino-2phenylindole (DAPI, Sigma-Aldrich) and coverslipped with antifading mounting medium (Vectashield, Vector Labs, Burlingame, CA, USA).

For nuclear stainings, an antigen retrieval protocol was applied. Sections were incubated with $10 \mathrm{mM}$ tri-sodium citrate buffer $(+0.05 \%$ Tween $20, \mathrm{pH} 6.0)$ for $30 \mathrm{~min}$ at $80^{\circ} \mathrm{C}$ and $20 \mathrm{~min}$ at room temperature.

Detection of EdU incorporation was performed using the Click-it EdU system (Life Technologies) according to the manufacturer's instructions.

\section{In situ hybridization}

In situ RNA hybridization was performed as previously described [65]. After dissection, postnatal or adult brains were fixed in $4 \%$ PFA at $4^{\circ} \mathrm{C}$ for 48 or $24 \mathrm{~h}$, respectively, cryoprotected in $30 \%$ sucrose at $4^{\circ} \mathrm{C}$ overnight, cryosectioned at $20 \mu \mathrm{m}$ on consecutive slides, and stored at $-80^{\circ} \mathrm{C}$. Sections were acetylated with $0.1 \mathrm{M}$ triethanolamine and $2.5 \mu \mathrm{L} / \mathrm{mL}$ acetanhydride for $10 \mathrm{~min}$ and additionally fixed in 4\% PFA at RT for $15 \mathrm{~min}$ before prehybridization for $4 \mathrm{~h}$ followed by 1 to $2 \mu \mathrm{g} / \mathrm{mL}$ probe hybridization for $16 \mathrm{~h}$ at $65^{\circ} \mathrm{C}$. The antisense $E 2-2$ [NM_013685], E2A [NM_011548], and HEB [NM_011544] probes were derived from plasmid constructs, whereas linearized templates were transcribed using a T7 RNA polymerase (Thermo Fisher Scientific, Waltham, MA). Anti-DIG FAB (1:2000 (Roche)) immunostaining was applied at $4^{\circ} \mathrm{C}$ overnight and subsequently developed in buffer containing BCIP $(175 \mu \mathrm{g} / \mathrm{mL})$ and NBT $(100 \mu \mathrm{g} / \mathrm{mL})$ for $12-48 \mathrm{~h}$.

\section{Microdissection and MAC sorting}

To determine the spatio-temporal E-protein expression pattern, the SVZ or the striatum were microdissected from mice aged P6 as described in previously published protocols [66]. In brief, NSCs and neuroblasts were isolated by magnetic affinity cell sorting (MACS) using conjugated antibodies against the transmembrane proteins Prominin-1, also known as CD133, and PSA-NCAM. Dissected tissues were pooled in Hanks buffered salt solution (Life Technologies) and dissociated using a trypsin-based kit following manufacturer's guidelines (Miltenyi Biotec, Bergisch Gladbach, Germany). Then, anti-Prominin-1 or anti-PSA-NCAM antibodies conjugated with magnetic beads (Miltenyi Biotec) were applied to the cell suspension for $30 \mathrm{~min}$ at $4^{\circ} \mathrm{C}$ before they were passed through MACS separator columns (Miltenyi Biotec). Sorted cells were snapfrozen for subsequent RT-qPCR. One litter represents 1 'n' number. 


\section{Gene expression analysis}

RNA was extracted, processed, and amplified from tissues/cells as previously described [32]. For RT-qPCR, $20 \mathrm{ng}$ of cDNA were loaded with $5 \mu \mathrm{m}$ of forward and reverse primers (Map2: fw_GCTGAAGCTGTAGCAGT CCTGAA, rv_GTGTTGGGCTTCCTTCTCTTGT; E2-2: $\mathrm{fw}$ _GGGAAAGCCCTAGCTTCGAT, rv_CCCACAGGAC TTGAAGGATTG; E2A: fw_TGGGCTCTGACAAGGAA CTGA, rv_CCGGCTCTTCCCATTGG; HEB: fw_CCAT CCCCAAATTCTGACGAT, rv_GCTGGCTCATCCCATT CG; $D c x$ : fw_CTGACTCAGGTAACGACCAAGAC, rv_T TCGAGGGCTTGTGGGTGTAGA; CD24: fw_ACATCTG TTGCACCGTTTCCCG, rv_CAGGAGACCAGCTGTGG ACTG; GFAP: fw_GCAGAAGCTCCAAGATGAAAC, rv_CCTTTCTCTCCAAATCCACAC; Id1: fw_CCTAG CTGTTCGCTGAAGGC, rv_CTCCGACAGACCAAG TACCAC; ABCG2: fw_CTCAACCTGCCCATTTCAA ATGCT, rv_GTTGGAAGTCGAAGAGCTGCTGAGA; Gadd45g: fw_CTGCTGTGAGAACGACATTG, rv_GG TCCTTCCATGTGTCCTCA; Ccng2: fw_CTACAGTGT TCCTGAGCTGC, rv_GTCTGAGCCACTTGGAAGTC; Btg2: fw_GCGAGCAGAGACTCAAGGTT, rv_CGGATA CAGCGATAGCCAGA; Prmt2: fw_CCACAGCAAGGTG CTCTTCT, rv_TGCATGGCTCAGAGAGACAG; FoxM1: $\mathrm{fw}_{\text {_CTACACTTGGATTGAGGACC, rv_CCATTGGCAG }}$ ATGTCTCTCG; $C d k 4$ : fw_GGACCTGAAGCCAGAGAA CA, rv_AGATACAGCCAACGCTCCAC), SYBR green mastermix (Roche), and DNAse/RNAse free $\mathrm{H}_{2} \mathrm{O}$ (SigmaAldrich) onto 96-well plates for LightCycler 480 (Roche). All samples were run in duplicates or triplicates, whereas glyceraldehyde-3-phosphate dehydrogenase (GAPDH: fw_CGACTTCAACAGCAACTCCCACTCTTCC, rv_TG GGTGGTCCAGGGTTTCTTACTCCTT) was used as reference gene. Relative gene expression was determined using the ${ }^{\Delta \Delta-} \mathrm{C}$ T method [67].

\section{Analysis}

Images were acquired with a laser scanning confocal microscope (Olympus IX 81, Olympus, Tokyo, Japan) equipped with a $20 \times$ or $40 \times$ objective, or with an epifluorescence microscope (Leica DM5500 B, Leica). Quantifications following in vivo electroporations are based on an average cell count of 254 successfully transfected cells per animal $(\mathrm{n} \geq 5)$. Each animal represented 1 ' $n$ ' number. Morphological criteria to define RGCs were bipolar morphology and apical connection to the LV lumen. Morphological criteria to define non-RGCs were absence of apical and basal processes (i.e., roundish appearance), and absence of contact to the LV lumen [31,32].

All data are expressed as mean and standard error of the mean $( \pm$ SEM). $P$ values were determined using unpaired $t$-test or two-way ANOVA followed by Dunnett's post hoc test (GraphPad Prism v5 software, San Diego, CA, USA).

\section{Additional file}

Additional file 1: (A) In contrast to the blockade of Ascl1-induced neuronal differentiation shown in Figure $1 C, d n E 47$ overexpression alone did not affect Map2 expression in NS5 cells kept in proliferative culture conditions (100 \pm 1.0 vs. $93.9 \pm 5.3)$. (B) Ki67 immunoreactivity revealed an increased non-RGC proliferation after $d n E 47$, when compared to empty control conditions, as shown in Figure 1E. (C \& D) Antigenic characterization of $\mathrm{Ki}^{+} 7^{+}$non-RGCs, demonstrated that both $\mathrm{Ascl} 1^{+}$type-C (C, Figure $2 \mathrm{C}$ ) and, to a lesser extent, Dcx type-A cells (D, Figure $2 C$ ) proliferate. (E-G) Representative immunostainings for detected changes in the expression of cell type specific markers; i.e., $R G C=\operatorname{Vimentin}^{+}(\mathbf{E})$, type- $\mathrm{C}=\mathrm{Ascl}^{+}(\mathbf{F})$, type-A $=\mathrm{Dcx}{ }^{+}(\mathbf{G})$, following $d n E 47$ expression, as quantified in Figure 2D-G. (H) Absence of cross-reactivity between shRNAs against E2A and E2-2 transcripts (see also Figure 4B). E2A mRNA expression was not reduced when shRNA against E2-2 was applied in vitro $(100 \pm 7.6$ vs. $111.5 \pm 1.1)$. Similarly, E2-2 mRNA expression was not reduced when shRNA against E2A was used (100 \pm 2.7 vs. $148.6 \pm$ 8.7). (I, J), Representative immunostainings for Dcx and Ascl1 illustrating an increased Dcx expression (I, quantified in Figure 5C) and unaltered Ascl1 expression (J, quantified in Figure 5D), when E2-2 was overexpressed. Arrows identify representative cells for each experimental condition. Quantifications were normalized to control conditions. Scale bars: B-G, I, J, 20 mm.

\section{Abbreviations}

bHLH: Basic-helix-loop-helix; CNS: Central nervous system; dnE47: Dominant-negative E47; dpe: Days post-electroporation; EdU: 5-ethynyl-2'-deoxyuridine; GFP: Green fluorescence protein; GoF: Gain-of-function; ISH: In situ hybridization; LoF: Loss-of-function; LV: Lateral ventricle; MACS: Magnetic affinity cell sorting; non-RGC: Non-radial glial cell; NSC: Neural stem cells; PFA: Paraformaldehyde; RGC: Radial glial cell; RMS: Rostral migratory stream; RT-qPCR: Real-time quantitative polymerase chain reaction; SVZ: Subventricular zone.

\section{Competing interests}

The authors declare that they have no competing interests.

\section{Authors' contributions}

$\mathrm{BF}, \mathrm{KA}, \mathrm{SR}$, and MF carried out the experimental work. AHC contributed expertise for the subcloning of plasmids. BF and OR wrote the manuscript. OR conceived the study. All authors read and approved the final manuscript.

\section{Acknowledgements}

$\mathrm{BF}, \mathrm{KA}$, and AHC were supported by a National Research Project grant (NRP63; 406340_128291) and by a research grant (31003A_127082) from the Swiss National Fund. MF and SR were supported by a grant from the Swiss National Fund (31003A_127082) and by the NCCR project 1, respectively. KA and $\mathrm{AHC}$ were also supported by personal grants from the Forschungskredit (K-41211-01-01) of the University of Zurich or from the Mexican Government (CONACYT), respectively.

\section{Author details}

${ }^{1}$ Brain Research Institute, ETH Zurich/University of Zurich, 8057 Zurich, Switzerland. ${ }^{2}$ Stem Cell and Brain Research Institute, Inserm U846 Lyon, 69675 Bron, France. ${ }^{3}$ Université de Lyon, Université Lyon I, 69003 Lyon, France.

Received: 16 July 2014 Accepted: 8 October 2014

Published: 29 October 2014

\section{References}

1. Ponti G, Obernier K, Guinto C, Jose L, Bonfanti L, Alvarez-Buylla A: Cell cycle and lineage progression of neural progenitors in the ventricular-subventricular zones of adult mice. Proc Natl Acad Sci U S A 2013, 110:E1045-E1054.

2. Doetsch F, Caille I, Lim DA, García-Verdugo JM, Alvarez-Buylla A: Subventricular zone astrocytes are neural stem cells in the adult mammalian brain. Cell 1999, 97:703-716.

3. Lois C, Alvarez-Buylla A: Long-distance neuronal migration in the adult mammalian brain. Science 1994, 264:1145-1148. 
4. Lledo P-M, Merkle FT, Alvarez-Buylla A: Origin and function of olfactory bulb interneuron diversity. Trends Neurosci 2008, 31:392-400.

5. Massari ME, Murre C: Helix-loop-helix proteins: regulators of transcription in eucaryotic organisms. Mol Cell Biol 2000, 20:429-440.

6. Ross SE, Greenberg ME, Stiles CD: Basic helix-loop-helix factors in cortical development. Neuron 2003, 39:13-25.

7. Knust E, Bremer KA, Vässin H, Ziemer A, Tepass U, Campos-Ortega JA: The enhancer of split locus and neurogenesis in drosophila melanogaster. Dev Biol 1987, 122:262-273.

8. Sasai $Y$, Kageyama $R$, Tagawa $Y$, Shigemoto $R$, Nakanishi $S$ : Two mammalian helix-loop-helix factors structurally related to drosophila hairy and Enhancer of split. Genes Dev 1992, 6:2620-2634.

9. Murre C, Bain G, Dijk MAV, Engel I, Furnari BA, Massari ME, Matthews JR, Ouong MW, Rivera RR, Stuiver MH: Structure and function of helix-loop-helix proteins. Biochim Biophys Acta 1994, 1218:129-135.

10. Ishibashi M, Ang S-L, Shiota K, Nakanishi S, Kageyama R, Guillemot F: Targeted disruption of mammalian hairy and Enhancer of split homolog-1 (HES-1) leads to up-regulation of neural helix-loop-helix factors, premature neurogenesis, and severe neural tube defects. Genes Dev 1995, 1:3135-3148.

11. Ohtsuka T, Ishibashi M, Gradwohl G, Nakanishi S, Kageyama R: Hes1 and Hes5 as Notch effectors in mammalian neuronal differentiation. EMBO J 1999, 18:2196-2207.

12. Rothschild G, Zhao X, lavarone A, Lasorella A: E proteins and Id2 converge on p57 Kip2 to regulate cell cycle in neural cells. Mol Cell Biol 2006, 26:4351-4361

13. Chen $\mathrm{H}$, Thiagalingam A, Chopra $\mathrm{H}$, Borges MW, Feder JN, Nelkin BD, Baylin SB, Ball DW: Conservation of the drosophila lateral inhibition pathway in human lung cancer: a hairy-related protein (HES-1) directly represses achaete-scute homolog-1 expression. Proc Natl Acad Sci U S A 1997, 94:5355-5360

14. Davis RL, Turner DL: Vertebrate hairy and enhancer of split related proteins: transcriptional repressors regulating cellular differentiation and embryonic patterning. Oncogene 2001, 20(58):8342-8357.

15. Alifragis $P$, Poortinga $G$, Parkhurst SM, Delidakis C: A network of interacting transcriptional regulators involved in drosophila neural fate specification revealed by the yeast two-hybrid system. Proc Natl Acad Sci U S A 1997, 94:13099-13104.

16. Norton JD: ID helix-loop-helix proteins in cell growth, differentiation and tumorigenesis. J Cell Sci 2000, 113:3897-3905.

17. H-s N, Benezra R: High levels of Id1 expression define B1 type adult neural stem cells. Cell Stem Cell 2009, 5:515-526.

18. Niola F, Zhao X, Singh D, Castano A, Sullivan R, Lauria M, Nam H-S, Zhuang $Y$, Benezra R, Bernardo DD, lavarone A: Id proteins synchronize stemness and anchorage to the niche of neural stem cells. Nat Cell Biol 2012, 14:477-487

19. Parras CM, Galli R, Britz O, Soares S, Galichet C, Battiste J, Johnson JE, Nakafuku M, Vescovi A, Guillemot F: Mash1 specifies neurons and oligodendrocytes in the postnatal brain. EMBO J 2004, 23:4495-4505.

20. Farah MH, Olson JM, Sucic HB, Hume RI, Tapscott SJ, Turner DL: Generation of neurons by transient expression of neural bHLH proteins in mammalian cells. Development 2000, 127:693-702.

21. Geoffroy CG, Critchley JA, Castro DS, Ramelli S, Barraclough C, Descombes P, Guillemot F, Raineteau O: Engineering of dominant active basic helix-loop-helix proteins that are resistant to negative regulation by postnatal central nervous system antineurogenic cues. Stem Cells 2009, 27:847-856.

22. Castro DS, Martynoga B, Parras C, Ramesh V, Pacary E, Johnston C, Drechsel D, Lebel-Potter M, Galinanes Garcia L, Hunt C, Dolle D, Bithell A, Ettwiller L, Buckley N, Guillemot F: A novel function of the proneural factor Ascl1 in progenitor proliferation identified by genome-wide characterization of its targets. Genes Dev 2011, 25:930-945.

23. Heng JIT, Tan S-S: The role of class I HLH genes in neural development have they been overlooked? Bioessays 2003, 25:709-716.

24. Bhattacharya A, Baker NE: A network of broadly expressed HLH genes regulates tissue-specific cell fates. Cell 2011, 147:881-892.

25. Roberts VJ, Steenbergen R, Murre C: Localization of E2A mRNA expression in developing and adult rat tissues. Proc Natl Acad Sci U S A 1993, 90:7583-7587

26. Ravanpay AC, Olson JM: E protein dosage influences brain development more than family member identity. J Neurosci Res 2008, 86:1472-1481.
27. Peverali FA, Ramqvist T, Saffrich R, Pepperkok R, Barone MV, Philipson L: Regulation of G1 progression by E2A and Id helix-loop-helix proteins. EMBO J 1994, 13:4291-4301.

28. Conti L, Pollard SM, Gorba T, Reitano E, Toselli M, Biella G, Sun Y, Sanzone S, Ying Q-L, Cattaneo E, Smith A: Niche-independent symmetrical self-renewal of a mammalian tissue stem cell. PLOS Bio/ 2005, 3:1594-1606.

29. Mehmood R, Yasuhara N, Oe S, Nagai M, Yoneda Y: Synergistic nuclear import of NeuroD1 and its partner transcription factor, E47, via heterodimerization. Exp Cell Res 2009, 315:1639-1652.

30. Beyeler S, Joly S, Fries M, Obermair FJ, Burn F, Mehmood R, Tabatabai G Raineteau O: Targeting the bHLH transcriptional networks by mutated $\mathrm{E}$ proteins in experimental glioma. Stem Cells 2014, 32(10):2583-2595.

31. Fernandez ME, Croce S, Boutin C, Cremer H, Raineteau O: Targeted electroporation of defined lateral ventricular walls: a novel and rapid method to study fate specification during postnatal forebrain neurogenesis. Neural Dev 2011, 6:1-12.

32. Azim K, Fischer B, Hurtado-Chong A, Draganova K, Cantu C, Zemke M, Sommer L, Butt A, Raineteau O: Persistent Wnt/beta-Catenin signaling determines dorsalization of the postnatal subventricular zone and neural stem cell specification into oligodendrocytes and glutamatergic neurons. Stem Cells 2014, 32(5):1301-1312.

33. Gong S, Zheng C, Doughty ML, Losos K, Didkovsky N, Schambra UB, Nowak $\mathrm{NJ}$, Joyner A, Leblanc $\mathrm{G}$, Hatten ME, Heintz N: A gene expression atlas of the central nervous system based on bacterial artificial chromosomes. Nature 2003, 425:917-925.

34. Basak O, Taylor $\mathrm{V}$ : Identification of self-replicating multipotent progenitors in the embryonic nervous system by high Notch activity and Hes5 expression. Eur J Neurosci 2007, 25:1006-1022.

35. Bain G, Maandag EC, Izon DJ, Amsen D, Kruisbeek AM, Weintraub BC, Krop I, Schlissel MS, Feeney AJ, van Roon M, van der Valk M, te Riele HPJ, Anton B, Cornelis M: E2A proteins are required for proper B cell development and initiation of immunoglobulin gene rearrangements. Cell 1994, 79:885-892.

36. Zhuang $Y$, Soriano $P$, Weintraub $H$ : The helix-loop-helix gene E2A is required for B cell formation. Cell 1994, 79:875-884.

37. Zhuang Y, Barndt RJ, Pan L, Kelley R, Dai M: Functional replacement of the mouse E2A gene with a human HEB cDNA. Mol Cell Biol 1998, 18:3340-3349.

38. Beckervordersandforth R, Tripathi P, Ninkovic J, Bayam E, Lepier A, Stempfhuber B, Kirchhoff F, Hirrlinger J, Haslinger A, Lie DC, Beckers J, Yoder B, Irmler M, Götz M: In vivo fate mapping and expression analysis reveals molecular hallmarks of prospectively isolated adult neural stem cells. Cell Stem Cell 2010, 7:744-758.

39. Li S, Mattar P, Dixit R, Lawn SO, Wilkinson G, Kinch C, Eisenstat D, Kurrasch DM, Chan JA, Schuurmans C: RAS/ERK signaling controls proneural genetic programs in cortical development and gliomagenesis. J Neurosci 2014, 34:2169-2190.

40. Ghysen A, Dambly-Chaudiere C: From DNA to form: the achaete-scute complex. Genes Dev 1988, 2:495-501.

41. Hallam S, Singer $E$, Waring $D$, Jin $Y$ : The $C$. elegans NeuroD homolog cnd-1 functions in multiple aspects of motor neuron fate specification. Development 2000, 127(19):4239-4252

42. Portman DS, Emmons SW: The basic helix-loop-helix transcription factors LIN-32 and HLH-2 function together in multiple steps of a C. elegans neuronal sublineage. Development 2000, 127:5415-5426.

43. Bertrand N, Castro DS, Guillemot F: Proneural genes and the specification of neural cell types. Nat Rev 2002, 3:517-530.

44. Casarosa S, Fode C, Guillemot F: Mash1 regulates neurogenesis in the ventral telencephalon. Development 1999, 126:525-534.

45. Vaessin H, Brand M, Jan LY, Jan YN: Daughterless is essential for neuronal precursor differentiation but not for initiation of neuronal precursor formation in Drosophila embryo. Development 1994, 120:935-945.

46. Hassan B, Vaessin H: Daughterless is required for the expression of cell cycle genes in peripheral nervous system precursors of Drosophila embryos. Dev Genet 1997, 21:117-122.

47. Flora A, Garcia JJ, Thaller C, Zoghbi HY: The E-protein Tcf4 interacts with Math1 to regulate differentiation of a specific subset of neuronal progenitors. Proc Natl Acad Sci U S A 2007, 104:15382-15387.

48. Prabhu S, Ignatova A, Park ST, Sun XH: Regulation of the expression of cyclin-dependent kinase inhibitor p21 by E2A and Id proteins. Mol Cell Biol 1997, 17:5888-5896. 
49. Pagliuca A, Gallo P, De Luca P, Lania L: Class A helix-loop-helix proteins are positive regulators of several cyclin-dependent kinase inhibitors' promoter activity and negatively affect cell growth. Cancer Res 2000, 60:1376-1382.

50. Perez-Moreno MA, Locascio A, Rodrigo I, Dhondt G, Portillo F, Nieto MA, Cano A: A new role for E12/E47 in the repression of E-cadherin expression and epithelial-mesenchymal transitions. J Biol Chem 2001, 276:27424-27431.

51. Cubillo E, Diaz-Lopez A, Cuevas EP, Moreno-Bueno G, Peinado H, Montes A, Santos V, Portillo F, Cano A: E47 and Id1 interplay in epithelial-mesenchymal transition. PLoS One 2013, 8:e59948.

52. Meredith A, Johnson JE: Negative autoregulation of Mash1 expression in CNS development. Dev Biol 2000, 222:336-346.

53. Palma V, Lim DA, Dahmane N, Sanchez P, Brionne TC, Herzberg CD, Gitton Y, Carleton A, Alvarez-Buylla A, Ruiz i Altaba A: Sonic hedgehog controls stem cell behavior in the postnatal and adult brain. Development 2005, 132:335-344.

54. Lim DA, Tramontin AD, Trevejo JM, Herrera DG, Garcia-Verdugo JM, Alvarez-Buylla A: Noggin antagonizes BMP signaling to create a niche for adult neurogenesis. Neuron 2000, 28:713-726.

55. Bonaguidi MA, Peng CY, McGuire T, Falciglia G, Gobeske KT, Czeisler C, Kessler JA: Noggin expands neural stem cells in the adult hippocampus. J Neurosci 2008, 28:9194-9204.

56. Azim K, Fiorelli R, Zweifel S, Hurtado-Chong A, Yoshikawa K, Slomianka L, Raineteau O: 3-dimensional examination of the adult mouse subventricular zone reveals lineage-specific microdomains. PLoS One 2012, 7:e49087.

57. Imayoshi I, Isomura A, Harima Y, Kawaguchi K, Kori H, Miyachi H, Fujiwara T, Ishidate F, Kageyama R: Oscillatory control of factors determining multipotency and fate in mouse neural progenitors. Science 2013, 342(6163):1203-1208.

58. Vinals F, Reiriz J, Ambrosio S, Bartrons R, Rosa JL, Ventura F: BMP-2 decreases Mash1 stability by increasing Id1 expression. EMBO J 2004, 23:3527-3537.

59. Li S, Mattar P, Zinyk D, Singh K, Chaturvedi CP, Kovach C, Dixit R, Kurrasch DM, Ma YC, Chan JA, Wallace V, Dilworth FJ, Brand M, Schuurmans C: GSK3 temporally regulates neurogenin 2 proneural activity in the neocortex. J Neurosci 2012, 32:7791-7805.

60. Welinder E, Mansson R, Mercer EM, Bryder D, Sigvardsson M, Murre C: The transcription factors E2A and HEB act in concert to induce the expression of FOXO1 in the common lymphoid progenitor. Proc Natl Acad Sci U S A 2011, 108:17402-17407.

61. Jones ME, Zhuang Y: Stage-specific functions of E-proteins at the beta-selection and T-cell receptor checkpoints during thymocyte development. Immunol Res 2011, 49:202-215.

62. Brill MS, Ninkovic J, Winpenny E, Hodge RD, Ozen I, Yang R, Lepier A, Gascon S, Erdelyi F, Szabo G, Parras C, Guillemot F, Frotscher M, Berninger B, Hevner RF, Raineteau O, Götz M: Adult generation of glutamatergic olfactory bulb interneurons. Nat Neurosci 2009, 12:1524-1536.

63. Winpenny E, Lebel-Potter M, Fernandez ME, Brill MS, Götz M, Guillemot F, Raineteau O: Sequential generation of olfactory bulb glutamatergic neurons by Neurog2-expressing precursor cells. Neural Dev 2011, 6:1-18.

64. Spiliotopoulos D, Goffredo D, Conti L, Di Febo F, Biella G, Toselli M, Cattaneo E: An optimized experimental strategy for efficient conversion of embryonic stem (ES)-derived mouse neural stem (NS) cells into a nearly homogeneous mature neuronal population. Neurobiol Dis 2009, 34:320-331.

65. Wilkinson DG, Nieto MA: Detection of messenger RNA by in situ hybridization to tissue sections and whole mounts. Methods Enzymol 1993, 225:361-373.

66. Azim K, Raineteau O, Butt AM: Intraventricular injection of FGF-2 promotes generation of oligodendrocyte-lineage cells in the postnatal and adult forebrain. Glia 2012, 60:1977-1990.

67. Pfaffl MW: A new mathematical model for relative quantification in real-time RT-PCR. Nucleic Acids Res 2001, 29:e45

doi:10.1186/1749-8104-9-23

Cite this article as: Fischer et al:: E-proteins orchestrate the progression of neural stem cell differentiation in the postnatal forebrain. Neural Development 2014 9:23.

\section{Submit your next manuscript to BioMed Central and take full advantage of:}

- Convenient online submission

- Thorough peer review

- No space constraints or color figure charges

- Immediate publication on acceptance

- Inclusion in PubMed, CAS, Scopus and Google Scholar

- Research which is freely available for redistribution 